\title{
Comparing The Machiavellianism Of Today's Indonesian College Students With U. S. College Students Of Today And The 1960s
}

Harry A Harmon, University of Central Missouri, USA

Robert L. Webster, Ouachita Baptist University, USA

Kevin L. Hammond, University of Tennessee at Martin, USA

\begin{abstract}
The tactics and strategies that were suggested by Niccolo Machiavelli in The Prince (1513) have become synonymous with manipulative and unethical practices. Machiavelli's writing to the politician has been used to describe business leaders as well. The business literature indicates that Machiavellian tactics do not guarantee success. The research we report examined the Machiavellian tendencies of college students in Indonesia and compare those results to the literature including the original U.S. student sample of the 1960s and the Harmon and Webster student sample published in 2002.
\end{abstract}

Keywords: Ethics, Machiavellian

\section{INTRODUCTION}

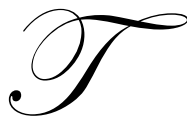

he tactics and strategies that were suggested by Niccolo Machiavelli in The Prince (1513) have become synonymous with manipulative and unethical practices. Machiavelli's writing to the politician has been used to describe business leaders as well. The business literature indicates that Machiavellian tactics do not guarantee success. The research we report examined the Machiavellian tendencies of college students in Indonesia and compare those results to the literature including the original U.S. student sample of the 1960s and the Harmon and Webster student sample published in 2002. Statistically significant differences are reported that support two hypotheses. A structured society and work force with limited mobility may explain the lower Machiavellian tendencies of Indonesian students relative to U.S. students. An unexpected finding is that Indonesian women students are more Machiavellian than their male counterparts.

A prince in Renaissance Italy, according to Machiavelli, needed to be able to adapt to the situation, be capable of manipulating individuals, and be able to foster relationships that successfully benefited the prince. If the prince could indeed accomplish those tasks without emotion or maintain an amoral attitude, the prince could expect success as a leader of the common man. A great deal of literature exists that examines the Machiavellianism of individuals in several occupations and organizations. This stream of literature developed primarily after Christie and Geis developed in the 1960s an instrument to measure the construct. The construct is measured and developed by statements that range from "Honesty is the best policy in all cases", to "The biggest difference between most criminals and other people is that criminals are stupid enough to get caught." Thus, the Machiavellian individual is generally described as manipulative and exploitive, seeks success (victory) through whatever means necessary, and is found in various groups of people. A person scoring high on the Machiavellian instrument would be deemed unethical vis-à-vis the ethical person. The business literature includes several research studies that examined the tendencies of the Machiavellian person and his or her subsequent success in the career field (Merritt 1991; 
Likierman 1989; Chonko 1982; Touhey 1973). Webster and Harmon (2002) provide a comprehensive discussion of the literature whereas only the more salient highlights are presented here.

The Christie and Geis (Studies in Machiavellianism, Academic Press, New York, 1970) scale has since been successfully used in many studies creating a body of literature that describes the Machiavellian manager. For example, Robinson and Shaver (1973) define a Machiavellian-orientation as a strategy to manipulate others in interpersonal situations. An earlier work by Calhoon (1969) noted that a Machiavellian person achieves individual and organization objectives through an aggressive, manipulative, exploitive and devious manner in dealing with other individuals. Gemmill and Heisler (1972) reported that the more Machiavellian manager in a highly bureaucratic structure did not do as well as the less Machiavellian manager. They suggested that the structure frustrated the higher Machiavellian manager because he or she had little opportunity to manipulate or influence other organization members. The higher Machiavellian managers reported more job strain and less job satisfaction than the lower Machiavellian managers. This suggests that the opportunity for advancement, or the freedom of choice, is an important moderator. That is, the individual needs to sense that he or she can affect a particular outcome by his or her behavior in trying to achieve that outcome. If an individual is free to choose a course of action, or is able to strive for a particular goal, the individual's behavior may well be different (e.g., self-serving) than the individual who is not afforded that possibility. Hunt and Chonko (1984) concluded that the marketing professional in the U.S. was no more Machiavellian than the rest of society, and therefore your daughter (or son) can indeed marry the marketing person.

Ferrell and Skinner (1988) argued that higher levels of ethical behavior are exhibited when a code of ethics exists and is enforced. However, early research indicates that leaders are indeed inclined to Machiavellian behavior and that inclination needs to be identified. In his research, Calhoon argued that there are multiple forces responsible for Machiavellian behavior. For example, the manager is influenced by ambition--consequent impatience, by organizational constraints on actions or incentives, and by ignorance--aggressiveness as the only way known to obtain results.

This research stream has merit in the college setting as well. Although professors may set the tone, or have certain expectations, there are forces similar to those in business situations that impact the student's use of Machiavellian actions. Numerous researchers have suggested that professors inform students about issues that affect their well being. Sirgy (1999) suggests that teachers inform students about the standards by which they will be evaluated. Teachers are bound to certain academic standards and should adhere to the codes of ethics of their academic/professional societies.

In Webster and Harmon (2002), the authors examined the Machiavellian tendencies of the contemporary college student and compared the results to the Christie and Geis sample of 1960s college students. The college student in 2001 was more Machiavellian than the 1960s student and men are more Machiavellian than women, as was the case in the 1960s. We examined the Machiavellian tendencies of college students in a different cultureIndonesia-and report gender differences and compare those results to the contemporary U.S. college student and the college student in the 1960s.

A situation might exist that is similar to the product life cycle. The product life cycle has been used to describe the process that new product ideas go through from introduction into the marketplace to ultimately decline and discontinuance. The foundation is that products, just like people, move through a series of stages during a "life span" that varies in length for a particular product idea. Although this modeled process has its critics, the model is found in much of the marketing literature to explain other situations as well, such as how salespeople mature overtime. We believe this process may be appropriate to describe the business strategies prevalent in a society. That is, the process could be used to describe a manager's trial of new strategies, or a different managerial style, or perhaps a seemingly more rational approach to "winning", however winning is defined. Specifically, as a person desires to win or to achieve success irrespective of methods, Machiavellian tendencies might become more attractive. A review of the product life cycle and Machiavellian literature suggests that like products, the college student's Machiavellianism moves through a life cycle so that those tendencies "mature" over time. We would suggest that the U.S. college student has a Mature Stage (or maturing) Machiavellianism, and the Indonesian student 
has a Machiavellianism that is in the Introduction Stage or the Growth Stage of the product life cycle. Recall from the literature that a structured environment tended to dampen the Machiavellianism of managers. The argument is that Indonesian students will also develop more Machiavellianism as the economy grows (or becomes more capitalistic), as the citizens and government become more democratic, and as larger numbers of young people are afforded education opportunities.

\section{RESEARCH QUESTIONS}

This research is a worthy endeavor to keep the research stream current by adding to the results reported in the literature from numerous studies and to bring the current generation of students into the literature. The research is framed by the influence that teaching method and course material have on the level of Machiavellianism. The Indonesian student data were collected at an urban college with faculty primarily from the U.S. A current sample of U.S. college students is included in the data set. Do the method of teaching and the teaching materials make a difference in the Machiavellian tendencies of individuals? Are Machiavellian tendencies learned (or not learned) early in life so that college-level instruction may result in only minor adjustments in the individual's judgment or behavior? The Indonesian students in our sample were being taught with the same textbooks and instructed in business procedures that would be common in the U.S. Indonesia, by population, is the largest Muslim country in the world. The United States is the largest country, by population, grounded in a Judeo-Christian value system. A comparison of students from very different backgrounds and value systems is an appropriate examination of the differences as well as the similarities. The Machiavellian survey instrument is a measurement instrument that can highlight those differences and similarities. Furthermore, as a country, the United States has a higher ranking (i.e., good, or less corrupt) on published corruption scales; whereas Indonesia has a lower ranking (i.e., bad, or more corrupt) on the same corruption scales. The Machiavellian instrument may aid in determining if a corrupted society (relative to other societies) is manifested in college student attitudes. Such a finding would be noteworthy in that college students generally pay more attention to, or, are more aware of, the ethics in decision-making than business people (Rayburn and Rayburn 1996).

Table 1

Comparison of Indonesia and United States

\begin{tabular}{|c|c|c|}
\hline & Indonesia & United States \\
\hline Population & $234,893,453$ & $290,342,554$ \\
\hline Age & 25.8 years & 35.8 years \\
\hline Male (Median) & 25.4 years & 34.5 years \\
\hline Female (Median) & 26.2 years & 37.1 years \\
\hline Literacy & $88.5 \%$ & $97 \%$ \\
\hline Males & $92.9 \%$ & $97 \%$ \\
\hline Female & $84.1 \%$ & $97 \%$ \\
\hline GDP per capita & $\$ 670$ & $\$ 37,600$ \\
\hline GDP-Composition & $17 \%$ agriculture & $2 \%$ agriculture \\
\hline By sectors & $41 \%$ industry & $18 \%$ industry \\
\hline Telephones & $42 \%$ service & $80 \%$ service \\
\hline
\end{tabular}

U.S. Government Document

Nations of the World, 2003, Grey House Publishing

Christie and Geis reported lower Machiavellianism ("Mach" scores) for individuals from less developed or less industrialized areas, and that lower income people generally record lower Mach scores. As the data in Table 1 indicate, Indonesia is less developed or industrialized than the U.S. For example, Indonesia has 28.34 telephones 
(line and mobile) per 1000 people versus 906.54 per 1000 people in the U.S. Perhaps more indicative is the difference in GDP, $\$ 670$ and $\$ 37,600$. The difference in the percentage of the GDP that is attributable to agriculture is quite large as well, 17\% in Indonesia and 2\% in the U.S. Thomson (2003) believes that Indonesia's greatest challenge is a sustained economic growth. The challenge seems particularly acute for the general population when the university educated individual has limited economic opportunity. Although other comparisons could be made, and the data provided might not explicitly distinguish the countries, we believe the data provide a flavor for different levels of industrial development and standard of living.

Loyalty and dedication have been shown to have significant influence on Machiavellian tendencies. Such tendencies were common in Renaissance Italy because of the constantly changing and shifting of politics. The need to adapt to the surroundings and power structure was a requirement for successful advancement. The argument has been that similar tendencies are commonplace in the contemporary organization as one looks out for self (Calhoon 1969). We believe that this self-interest motivation would not be as prevalent or as strong in a structured and less mobile society. Indonesia would seem to fit that description as it struggles to reform its governance and political accountability. The country has been described as a "fledgling democracy" with its 1945 constitution to serve as the foundation for a republic in a predominately Muslin country (Thomson 2003). If the labor force is immobile, or incapable of responding to better opportunities elsewhere, a degree of rigidity develops that creates structure. We would therefore expect Indonesian students to be lower Machs when compared to U.S. students, and test the following hypotheses:

- Hypothesis 1: Indonesian college students (accounting and management) report lower Machiavellian scores than U.S. college students of the 1960s.

- Hypothesis 2: Indonesian college students (accounting and management) report lower Machiavellian scores than current U.S. college students.

Education has been shown to be an influence on the individual's Machiavellianism. In the Christie and Geis research and again Webster and Harmon the results confirmed that hypothesis. Specifically, persons with a higher level of education are generally the higher Mach persons. Although literacy rate is not the same as education level, a comparison of literacy rates across countries may be an appropriate proxy for a society's educational development relative to another society's development even though the comparison is made with university students. Note that the data in Table 1 indicate literacy rates of $88.5 \%$ and $97 \%$ for Indonesia and U.S. Also note that the difference between the literacy reported for Indonesian men and women does not exist in the U.S.

The corporate scandals in the U.S., e.g., Enron, focus primarily on the firm's accounting practices. Because of the great deal of attention this scandal and others have drawn, we would reasonably expect the classroom instruction to include more emphasis placed on ethical business practices. The increased emphasis would be more apparent in the accounting discipline because of its codified accounting practice standards, vis-à-vis other business disciplines with standards that are perhaps amorphous. The Indonesian sample included accounting students and management students who responded to the same questionnaire. We expect the accounting majors to report lower Machiavellian scores than the management majors because there is a standard of ethics, or generalized code of conduct and accepted accounting methods that can be internalized.

- Hypothesis 3: Accounting majors will report lower Machiavellian mean scores than do management majors.

The literature would suggest that men (irrespective of educational level) report a higher Machiavellian score than women. Furthermore, the literacy rates of Indonesian men versus women would suggest a significant difference in the Machiavellian scores within the Indonesian sample.

- Hypothesis 4: The male Indonesian college students report higher Machiavellian scores than female Indonesian college students. 


\section{METHODOLOGY}

We used the Christie and Geis 20-item Mach IV scale. The scale is in the Likert format, anchored by Strongly Disagree (1) and Strongly Agree (7), and includes reverse scored items so that a high score indicates a high Machiavellian score. We follow the format used in previous research (Christie and Geis 1970; Hunt and Chonko 1984). A total Machiavellian score is computed by summing the 20 items and adding a constant of 20 to all scores. Therefore, the maximum score is $160(7.0 * 20$ items +20$)$, and the minimum score is $40(1.0 * 20+20)$. The data reported in the tables reflect this method of computation.

The computed Cronbach's alpha of .69 indicates the scale is an appropriate measure of the construct and compares favorably with previous research, Christie and Geis (.79) and Hunt and Chonko (.76). Our questionnaire collected gender and an additional classification question to further distinguish the student groups and to possibly capture the underlying influence. Specifically, students provided their major. As had been done in the previous research, the purpose of the study was not explained in detail to avoid or reduce a response demand effect.

\section{RESULTS}

The results are presented in Table 2 and Table 3. A summary comparison of the current research, the Webster and Harmon research, and the Christie and Gies research is presented in Table 4. A score over 100 is generally considered to be high Machiavellian (Hunt and Chonko 1984). Our tables follow the presentation format used by Hunt and Chonko to facilitate the discussion. Additionally, note that the current sample of Indonesian students has the smallest standard deviation, thereby indicating less variance among student responses. This result possibly provides credence for the argument of a structured society and less mobile workforce. The Indonesian sample data are compared to the Webster and Harmon data collected from college students in the Midwest and Southwest, areas relatively conservative when compared to the Christie and Geis sample.

Table 2

Indonesian College Students

Machiavellianism

t-test by major

\begin{tabular}{|c|c|c|c|c|}
\hline & \multicolumn{2}{|c|}{ Men } & Standard Deviation & Significance \\
\hline Accounting & Sample Size & Mean & 10.29 & $\mathrm{n} / \mathrm{s}$ \\
\hline Management & 54 & 80.70 & 8.64 & \\
& 52 & 82.6 & & \\
\hline & & Women & Significance \\
\hline Accounting & Sample Size & Mean & Standard Deviation & $\mathrm{n} / \mathrm{s}$ \\
\hline Management & 111 & 84.92 & 10.82 & \\
\hline
\end{tabular}

\begin{tabular}{|c|c|c|c|c|}
\hline & \multicolumn{3}{c}{ All } & \\
\hline & Sample Size & Mean & Standard Deviation & Significance \\
\hline Accounting & 165 & 83.54 & 9.90 & $\mathrm{n} / \mathrm{s}$ \\
\hline Management & 97 & 83.40 & 9.77 & \\
\hline
\end{tabular}

Measured on 7-point scale where a higher number = higher Machiavellianism 
Table 3

Indonesian College Students

Machiavellianism

t-test by sex

\begin{tabular}{|c|c|c|c|c|}
\hline Sex & Sample Size & Mean & Standard Deviation & Significance \\
\hline Male & 106 & 81.37 & 9.50 & 0.04 \\
\hline Female & 156 & 84.93 & 9.83 & $\mathrm{t}=2.92$ \\
\hline
\end{tabular}

Measured on 7-point scale where a higher number $=$ higher Machiavellianism

Table 4

U.S., Indonesian, Christie \& Gies Machiavellianism

\begin{tabular}{|c|c|c|c|c|c|c|c|c|c|}
\hline & \multicolumn{3}{|c|}{ Sample Size } & \multicolumn{3}{c}{ Mean } & \multicolumn{3}{c|}{ Standard Deviation } \\
\hline & All & Male & Female & All & Male & Female & All & Male & Female \\
\hline US & 240 & 107 & 133 & 92.02 & 93.48 & 90.84 & 10.13 & 9.50 & 10.50 \\
\hline C \& G & 1782 & $\mathrm{nr}$ & $\mathrm{nr}$ & 90.7 & $\mathrm{nr}$ & $\mathrm{nr}$ & 14.3 & $\mathrm{nr}$ & $\mathrm{nr}$ \\
\hline
\end{tabular}

$\mathrm{nr}=$ not reported in the study

Measured on 7-point scale where a higher number $=$ higher Machiavellianism

The Indonesian student sample reports lower Machiavellian scores than do the current U.S. students, and the 1960s college student. Thus hypotheses 1 and 2 are supported. The mean scores for the Indonesian sample are lower in each comparison group (all students and gender). The results provide some evidence that societal influences may well determine the student's Machiavellian tendencies, or have a stronger impact than does the classroom instruction. The data in Table 2 reject hypothesis 3, i.e., there is no statistically significant difference by college major for Indonesian students, additional evidence of a societal influence. The statistically significant results in Table 3 indicate lower Machiavellian scores for Indonesian men than women. This result refutes the expectation that a higher level of education (i.e., using literacy rate as a proxy) is associated with higher Machiavellian scores; and the expectation that women are less Machiavellian than men. The results reject hypothesis 4, women, not men, are the more Machiavellian.

\section{CONCLUSION}

The results highlight differences across countries and cultures in the Machiavellian tendencies of college students. Although these differences are quite striking, what is unclear is the trend over time of mean scores of Indonesian students. Recall that the different educational level (i.e., literacy rate) of men and women reported for Indonesian students does not exist in the U.S. Certainly we would not claim that college students are indicative of literacy rates for the general population of either country, but merely a potential indicator of a trend that is differentiated by gender and begins in childhood.

We would also conclude that a society's norms and accepted practices have a significant influence on an individual's Machiavellian tendencies. This conclusion is amplified by the lack of difference in the scores reported for college majors. The difference in the Machiavellianism of accounting majors and management majors was not statistically significant. Although Webster and Harmon report their student data as business or non-business and do not report their data by college major, the conclusion is not diminished. The Indonesian business student, regardless of major, reported a lower Machiavellian mean score than U.S. students in 2002 and the 1960s. The literature indicates that a business code of ethics must be enforced to change ethical behavior (Rayburn and Rayburn 1996). Our results seem to confirm that argument if we presume that the business student has not entered the workplace with its code of ethics but rather adheres to a societal macro-sense of ethics. To follow the Hunt and Chonko 
response to the question "Would you want your son or daughter to marry a marketing person?" we would say yes to both Indonesian management and accounting majors.

However, will the Indonesian student become more Machiavellian over time as did the U.S. student from the 1960s to 2002? If so, would that indicate that the Indonesian student is "catching up" and following a similar progression? Will the Indonesian population evolve into a more Machiavellian people over time? Do the results indicate that Indonesian women are more assertive (or believe they need to be more assertive) and hence more Machiavellian to enter the workforce and succeed in business? Alternatively, are the higher scores for Indonesian women reported here an anomaly? Although our research does not answer those questions it may provide a basis for future research. Until those questions are answered we would conclude that a structured society and less mobile workforce is the less Machiavellian population. Another study at some future date with Indonesian students or adult work force may provide evidence of a trend. An anonymous reviewer suggested a similar study would be appropriate for countries with an emerging economy, such as India and China. Such a study may offer further evidence that a trend exists, and that as an increasing economy develops, the managerial talent (or future talent) of that country displays a maturing Machiavellianism.

\section{AUTHOR INFORMATION}

Harry A. Harmon is Professor of Marketing at University of Central Missouri, and the 2008 Distinguished Professor for the College of Business. He received the D.B.A. from Louisiana Tech University. He is published in Journal of Business \& Industrial Marketing, Psychology and Marketing, Journal of Marketing Communications, Marketing Intelligence and Planning, Journal of Marketing Theory \& Practice, other journals and various national proceedings.

Robert L. Webster earned a DBA from Louisiana Tech University and is a Certified Government Financial Manager (CGFM). He currently holds the George Young Chair of Business and is Chair of the Department of Accounting at Ouachita Baptist University in Arkadelphia, Arkansas.

Kevin L. Hammond is Professor of Marketing at University of Tennessee at Martin. He received the D.B.A. from Louisiana Tech University. His research interests include sales management/channels of distribution and methodology. He is published in such journals as the Psychological Reports, Marketing Intelligence and Planning, Journal of Marketing Theory \& Practice and Southern Business Review.

\section{REFERENCES}

1. Calhoon, R. P. (1969), "Niccolo Machiavelli and the Twentieth Century Administrator," Academy of Management Journal, (June).

2. $\quad$ Chonko, L. B. (1982), "Are Purchasing Agents Machiavellian?" Journal of Purchasing and Materials Management, 18 (Winter), 15-20.

3. Christie, R. and Geis, F. L. (1970), Studies in Machiavellianism, New York: Academic Press.

4. $\quad$ Ferrell, O. C. and Skinner, S. J. (1988), "Ethical Behavior and Bureaucratic Structure in Marketing Research Organizations." Journal of Marketing Research 25 (February), 103-109.

5. Gemmill, G. R. and Heisler, W. J. (1972), "Machiavellianism as a Factor in Managerial Job Strain, Job Satisfaction, and Upward Mobility," Academy of Management Journal (March).

6. Hunt, S. D. and Chonko,L. B. (1984), "Marketing and Machiavellianism." Journal of Marketing 48, 30-42.

7. Likierman, A. (1989), "Ethical Dilemmas for Accountants: A United Kingdom Perspective." Journal of Business Ethics 8, 617-629.

8. Machiavelli, N. (1513) (1966), The Prince, translated by Daniel Donno, New York: Bantam Books.

9. $\quad$ Merritt, S. (1991), "Marketing Ethics and Education: Some Empirical Findings." Journal of Business Ethics 10, 625-632.

10. Rayburn, J. M. and Rayburn, L. G. (1996), "Relationship Between Machiavellianism and Type A Personality and Ethical-Orientation." Journal of Business Ethics 15, 1209-1219. 
11. Sirgy, M. J. (1999), "Social Responsibility and the Marketing Educator: A Discussion Document." Journal of Business Ethics 19, 193-206.

12. Thomson, W. R. (2003), Nations of the World, A Political, Economic \& Business Handbook, 2003Third Edition, Millerton, NY: Grey House Publishing.

13. Touhey, J. C. (1973), "Intelligence, Machiavellianism, and Social Mobility," British Journal of Social and Clinical Psychology, 12 (February), 34-37.

14. U.S. Government Document: available at: wwwodci.gov/cia/publications/factbook.

15. Webster, R. L. and Harmon, H. A. (2002), "Comparing Levels of Machiavellianism of Today's College Students with College Students of the 1960s," Teaching Business Ethics, 6, 435-445. 


\section{APPENDIX}

Please respond to the following statements candidly...there are no "right" or "wrong" answers. Use the following scale to report your agreement with the following statements. Write a number to the left of the statement on the blank line. (Scale intentionally omitted here)

1.___ The best way to handle people is to tell them what they want to hear.

2. When you ask someone to do something for you, it is best to give the real reasons for wanting it, rather than giving reasons which might carry more weight.

3.____ Anyone who completely trusts anyone else is asking for trouble.

4.___ It is hard to get ahead without cutting corners here and there.

5.___ Honesty is the best policy in all cases.

6.___ It is safest to assume that all people have a vicious streak, and it will come out when they are given a chance.

7.___ Never tell anyone the real reason you did something unless it is useful to do so.

8.__ One should take action only when sure it is morally right.

9.___ It is wise to flatter important people.

10.___ All in all, it is better to be humble and honest than important and dishonest.

11.___ Barnum was very wrong when he said there's a sucker born every minute.

12.___ People suffering from incurable diseases should have the choice of being put painlessly to death.

13. It is possible to be good in all respects.

14._Most people are basically good and kind.

15._There is no excuse for lying to someone else.

16.___ Most men forget more easily the death of their father than the loss of their property.

17.___ Most people who get ahead in the world lead clean, moral lives.

18.___ Generally speaking, men won't work hard unless they're forced to do so.

19. The biggest difference between most criminals and other people is that criminals are stupid enough to get caught.

20.___ Most men are brave.

Gender $\quad$ M $\quad$ F $\quad$ Your Major 
NOTES 